\title{
ECE2016 - like-minds meet in Munich
}

The endocrinology community gathered in Munich, Germany, in May for the European Congress of Endocrinology 2016 (ECE2016). More than 3,200 delegates from 86 different countries attended the 4 days of talks and lively debates organised by the European Society for Endocrinology.

One of the most enjoyable plenary talks was given by Jason Carroll from Cambridge, UK, who provided an overview of his group's research on oestrogen receptor-mediated transcription in breast cancer. Other plenary sessions that had much interest from the delegates, included the role of noncoding RNAs in endocrine-like signalling, endocrine disruption in the thyroid, and the initial trial results from a study into the effects of longterm testosterone use in men.

Of the many excellent symposiums, those on thyroid dysfunction in pregnancy and the chronic syndromes of patients previously treated for pituitary diseases (on which we have a new Review) were particularly popular, with an extra room set up for those unable to find a seat in the main session.
Introduced at ECE2015, and making a welcome return this year, were the New Scientific Approaches sessions, in which basic researchers provide an overview of new techniques for their clinical counterparts. For me, the talk by Monica Laronda from Northwestern University, Chicago, IL, USA was a stand-out. Laronda is developing bioprosthetic ovaries to restore ovarian function in women who had cancer treatment in childhood.

The 'for and against' debates also proved popular, with a live vote from the audience via a smartphone application adding a new dimension to the session. Overall the meeting provided an excellent forum for endocrinologists of all disciplines to exchange ideas and develop new collaborations. We look forward to ECE2017, which next year will be held in Lisbon, Portugal.

Tim Geach

FURTHER READING All abstracts from the meeting can be found at http://www.ece2016.org | Romijn, J.et. al. The chronic syndromes after previous treatment of pituitary tumours. Nat. Rev. Endocrinol. http://dx.doi.org/10.1038/nrendo.2016.84 (2016) 